Gerión. Revista de Historia Antigua

ISSN: 0213-0181

\title{
Estilo de vida durante el priscilianismo: aproximaciones bioarqueológicas ${ }^{1}$
}

\author{
Olalla López-Costas ${ }^{2}$
}

Recibido: 15 de febrero de 2021 / Aceptado: 21 de mayo de 2021

Resumen. Trato de reconstruir aquí las principales características de la vida diaria durante el priscilianismo en Galicia. A través de una revisión bibliográfica de las aproximaciones bioarqueológicas, que van desde evidencias aportadas por las turberas, los restos vegetales y animales, a los esqueletos humanos, reconstruyo las principales características del siglo IV al VI y sus diferencias con el periodo anterior. Los puntos más destacados son un súbito empeoramiento del clima, una mayor intensidad de la erosión de los suelos y de la destrucción de los bosques, además de la probable modificación de los hábitos alimentarios, incluyendo una mayor dependencia de productos marinos y mijos. En base a esta información, intento comprender si alguna de estas modificaciones pudo responder o estar conectada con esta nueva forma de vida religiosa en el noroeste peninsular o, al menos, comprender mejor cómo era la vida diaria de las personas.

Palabras clave: paleodieta; paleoambiente; Antigüedad tardía; Galicia; clima; contaminación.

\section{[en] Lifestyle during Priscillianism: Bioarchaeological Approaches}

Abstract. By analyzing bioarchaeological proxies -from evidence provided by peat records, plant and animal remains, to human skeletons- I aim to reconstruct the main features sketching lifestyle during Priscillianism (AD $4^{\text {th }}$ to $6^{\text {th }}$ centuries) as compared to the previous period by reviewing published literature. A sudden climate deterioration, increase in soil erosion, forest decline and a possible modification in diet, which became more dependent on marine resources and millets, are the main observed findings. Based on this information, I try to understand if some of these characteristics responded to, directly or indirectly, the new religious way of life in Nonwestern Iberia, or at least to understand better the everyday life of these societies.

Keywords: Paleodiet; Paleoenvironment; Late Antiquity; Galicia; Climate; Pollution.

Sumario. 1. Reconstruyendo el estilo de vida. 2. Un clima cambiante. 3. El no retorno del bosque y el cambio en el uso del suelo. 4. Modificaciones en la explotación de los metales. 5. Una alimentación que se adapta. 6. Breves apuntes sobre la morfología, salud, enfermedad y costumbres funerarias. 7. La vida en tiempos de Prisciliano y de los priscilianistas, una reflexión. 8. Referencias bibliográficas.

Cómo citar: López-Costas, O. (2021): Estilo de vida durante el priscilianismo: aproximaciones bioarqueológicas, en Gerión 39(2), 775-800.

1 Este trabajo fue redactado bajo la financiación del proyecto "Pollutio: Contaminación metálica ambiental en poblaciones de Hispania entre los siglos I al V a través de los restos óseos" - Plan Nacional Retos JIN 2019 (PID2019-111683RJ-I00) Ministerio de Ciencia e Innovación. Proyecto realizado con la Beca Leonardo a Investigadores y Creadores Culturales 2020 de la Fundación BBVA. Mis agradecimientos a Antonio Martínez Cortizas y a Pedro López Barja por sus comentarios y ayuda.

2 Universidade de Santiago de Compostela - Stockholm University.

E-mail: olalla.lopez@usc.es

ORCID: 0000-0002-6499-226X 


\section{Reconstruyendo el estilo de vida ${ }^{3}$}

El estilo de vida es uno de los aspectos que nos acercan en mayor medida a lo que supone el día a día de una sociedad. Existen varias definiciones y muchas maneras de entenderlo, que van desde lo individual a lo colectivo. ${ }^{4}$ Lo concibo como las particularidades que definen la vida diaria desde un punto de vista directo y físico; tales como qué salud tienes, cuál es tu dieta, a qué actividades dedicas tus días o tus posibilidades de obtener los recursos necesarios. Estas se unen a otras externas o más amplias que terminan de perfilar la identidad individual, tales como la clase social, las creencias, la cultura, la economía y finalmente el ambiente físico. Pertenecen las primeras a aquellas preguntas que se pueden intentar responder desde el estudio de los restos humanos (osteología, osteoarqueología, antropología física). Otras disciplinas como la zooarqueología o la paleobotánica nos ayudan a distinguir el uso que una comunidad hace de los recursos animales y vegetales $\mathrm{y}$, aunque no proporcionan información directa de las personas, son buenos proxies (marcadores, aproximaciones). En lo relativo a las segundas, se realiza un salto a una mayor escala y es aquí donde las reconstrucciones paleoambientales, la arqueología funeraria o la arqueotanatología juegan su papel. Los aspectos y disciplinas mencionadas se relacionan entre sí englobadas en un supra-concepto que podríamos denominar bioarqueología o uso de los proxies biológicos para reconstruir el pasado de los seres humanos. En todos los niveles caracterizados previamente, la historiografía proporciona información legítima. El complemento de la bioarqueología surge de la existencia de periodos o atributos "oscuros" no fácilmente abarcables por falta de fuentes; en otros casos son algunos grupos humanos los que están silenciados (ej. mujeres, enfermos, niños), o simplemente puede proporcionar consideraciones adicionales. Complementarias una de la otra, la historiografía y la bioarqueología tienen, en mi opinión, más futuro si siguen un camino común, rehuyendo los recorridos paralelos que les han caracterizado hasta ahora.

Como parte de este número especial sobre Prisciliano, en estas líneas trato de reunir todos los aspectos en los que la bioarqueología proporciona información (no solo datos) sobre un periodo concreto, aquel donde el priscilianismo estuvo vigente (siglos IV al VI), y su inmediato anterior y posterior, ${ }^{5}$ mediante una revisión crítica de los estudios publicados hasta el momento. Trabajo aquí con una gran variedad de "archivos" bioarqueológicos y paleoambientales, que al igual que si se tratara de las fuentes documentales, almacenan la información del pasado en señales macroscópicas, físicas y químicas. El área que acoto es la actualmente constituida por la comunidad autónoma de Galicia, en el noroeste de España. En los siguientes apartados pongo especial énfasis en señalar las características que particularizan cada tipo de proxy y archivo bioarqueológico, así como sus certidumbres y sus limitaciones, para que los lectores puedan desarrollar una idea de conjunto de la envergadura de cada uno dentro de mi discurso. Mi objetivo final es aportar información sobre la vida cotidiana de las gentes que vivieron en la Antigüedad Tardía, siendo conscientes

\footnotetext{
Todas las fechas de este artículo son d.C. a menos que se especifique lo contrario.

Sobel 2013, 7-30, lo define como "modo de vida" y concluye que no está claro si el estilo de vida pertenece a un individuo o a agregaciones de individuos. Me alejo de las definiciones filosóficas o relacionadas con el estatus socioeconómico debatidas por este autor, y me centro en un aspecto físico.

$5 \quad$ Ver los trabajos de Chadwick 1976; Escribano Paño 1996; Piay 2019.
} 
de que desgraciadamente los "archivos" analizados nunca nos podrán informar de cómo pensaban o cómo sentían. ${ }^{6}$

\section{Un clima cambiante}

El final del periodo romano constituye un momento de cambios que afectaron a los seres humanos no solo cultural o socialmente, sino también a nivel climático. En Galicia tenemos la ventaja de contar con una considerable extensión de turberas en algunas zonas de montaña, como la sierra del Xistral. Los depósitos de turba acumulan a lo largo del tiempo señales de cambios ambientales dejando un registro, en principio imperturbable, del ambiente de ese momento. Aspectos tales como las condiciones climáticas o el registro metálico, proxy de contaminación ambiental, quedan registrados en la turba que se forma coetáneamente (mediante su incorporación a través de los organismos vivos (plantas) o su deposición directa desde la atmósfera) y son progresivamente englobados en el depósito turboso a medida que este aumenta en espesor por formación de nuevas capas de turba en superficie. El depósito acumulativo de la misma hace que las modificaciones en profundidad sean limitadas, por lo que dichas características del ambiente quedan archivadas en la materia orgánica e inorgánica que conocemos como turba, cuya edad aumenta con la profundidad. En estas turberas se han obtenido registros que retroceden en el tiempo hasta 10.000 años, proporcionando una visión amplia de los cambios en el ambiente durante periodos de mayor o menor presión humana sobre el mismo. Por esa razón se las conoce como "archivos ambientales", ya que funcionan de manera similar a las fuentes escritas, encapsulando la información de un determinado momento. Los principales archivos ambientales para reconstruir el clima son los hielos polares, los sedimentos finos de lagos y las turberas. De estos archivos, para Galicia, y debido a su extensión, las últimas permiten hacer una reconstrucción regional.

En el caso que nos atañe, ha sido posible obtener una reconstrucción climática de los últimos 4.000 años a partir de la turbera de Penido Vello (Serra de O Xistral, norte de Lugo), la cual revela importantes cambios climáticos en el periodo objeto de este trabajo. ${ }^{7}$ Desde el cambio de era se puede observar un aumento de las temperaturas constituyendo el periodo conocido como Óptimo Climático Romano y que se caracteriza en esta zona por temperaturas elevadas con alguna caída menor y una humedad estable y relativamente baja. ${ }^{8} \mathrm{~A}$ partir del siglo IV se observa una modificación en la humedad, la cual se vuelve más inestable, con aumentos significativos pero cambiantes entre el 300 y el $600 .{ }^{9}$ Sin embargo, no hay evidencias de cambios en los gradientes de humedad con respecto a la actualidad ${ }^{10}$ es decir, las zonas de Galicia que son relativamente más secas ahora también lo habrían sido en el pasado, y lo mismo sucede con las más húmedas. Un intenso aumento de la

\footnotetext{
6 La información de carácter histórico-social no basada en estudios bioarqueológicos es abordada de manera más sucinta por razones de espacio y para evitar redundancias con otros trabajos de este número especial.

Martinez Cortizas et alii 1999.

Mighall et alii 2006.

Mighall et alii 2006.

Martínez Cortizas - Pérez Alberti 1999.
} 
humedad se detecta en torno al siglo IV. ${ }^{11}$ A esta evolución variable se le une un deterioro térmico relativamente súbito desde mediados del siglo IV, que alcanza su mínimo de temperaturas en torno al 500. Las temperaturas se empezaron a recuperar ligeramente alrededor de un siglo después. ${ }^{12}$ Uno de nuestros estudios recientes ha condensado los índices de humedad en uno solo, obteniendo para el noroeste una cronología similar a la anteriormente explicada. ${ }^{13}$

Para la comprensión de esta información y su grado de validez en el trabajo de reconstrucción histórica, ha de tenerse en cuenta que la información proporcionada por las turberas, aunque está directamente conectada al ámbito local, a nivel climático refleja modificaciones a escala regional. Por lo tanto, se trata de una buena aproximación al clima en el noroeste de España, o al menos la mejor aproximación que tenemos. No obstante, dicha reconstrucción cuenta con desventajas propias del archivo que se estudia. Los testigos de turba suelen tener una resolución muy por debajo de la preferencia del historiador, puesto que los análisis se realizan en secciones de 1 a $5 \mathrm{~cm}$, que representan periodos relativamente largos de tiempo (de décadas a centurias). Asimismo, es importante considerar los modelos cronológicos construidos en estos trabajos, es decir, asegurarnos de que cuentan con suficientes dataciones y son robustos. Finalmente, en nuestra interpretación de estas variaciones, como historiadores hemos de tener presente que por muy bueno que sea dicho modelo siempre posee incertidumbres, de modo que ligeras modificaciones en el modelo cronológico pueden llevarnos a cambios en la asignación temporal. Por ello, el deterioro climático que se observa claramente a inicios del siglo IV pudo, en realidad, haber ocurrido unas décadas antes o después.

\section{El no retorno del bosque y el cambio en el uso del suelo}

Ligado o no a este deterioro climático, las turberas y otros archivos ambientales, como los suelos coluviales, han revelado modificaciones importantes en la extensión de los bosques. El periodo romano se caracterizó por una caída en la cobertura arbórea, pero también por un aumento de especies cultivadas o manejadas, como el castaño o el olivo ${ }^{14}$ (reflejado en el aumento del polen de dichas especies en los registros polínicos). Sin embargo, el estudio de turberas ha revelado una recuperación de la cobertura arbórea asociada al periodo que nos atañe y que empieza en torno a mediados del siglo IV, alcanzando el máximo hacia el 450, con ligeras variaciones según los testigos analizados. ${ }^{15}$ Esto indica que hubo un descenso en la presión sobre las principales especies de árboles que forman el bosque atlántico, es decir, en los registros aumenta, entre otros, el polen de las especies del género Quercus, lo que se interpreta como una recuperación de la superficie ocupada por robledales. Las variaciones cronológicas con respecto al máximo de esta recuperación son fruto de la anteriormente mencionada

\footnotetext{
11 Schellekens et alii 2011, en muestras datadas entre los años 270-385. Se observa también un máximo de humedad en una muestra datada en 640, no incluida al tratarse de una medida puntual.

2 Martínez Cortizas et alii 1999.

Martínez Cortizas et alii 2019.

Martínez Cortizas et alii 2005; Silva-Sánchez et alii 2014.

15 Muñoz Sobrino et alii 1997; Martínez Cortizas et alii 2005; Mighall et alii 2006; Silva-Sánchez et alii 2014; Martínez Cortizas et alii 2019.
} 
incertidumbre en el modelo cronológico y la variabilidad cronológica local, ya que se cubre una geografía amplia (archivos situados en el Xistral hasta los Ancares y los Montes de O Bocelo).

Los estudios polínicos también indican que a este periodo de breve recuperación sigue una drástica reducción del bosque. Esta bajada empieza en torno al 500 y alcanza un mínimo de cobertura arbórea entre el $600-700 .{ }^{16} \mathrm{Si}$ bien existen variaciones que llegan a situar esta caída en fechas tan tardías como el siglo X, ${ }^{17}$ se trata de registros con una resolución cronológica baja (pocas dataciones radiocarbónicas) por lo que empleamos preferentemente aquellos que cuentan con modelos cronológicos más fiables. En algunas zonas de montaña del interior, como los Ancares y O Courel (este y sur de Lugo, respectivamente), se observa un aumento del abedul en substitución del robledal, ${ }^{18}$ en la sierra do O Bocelo, cerca de Santiago de Compostela, aumentan los alisos, probablemente ligados a la mayor humedad, ${ }^{19}$ mientras que en el Xistral se produce un descenso de todas las principales especies arbóreas. ${ }^{20}$ Esto indica que existió una diversidad de respuestas. Esta deforestación parece afectar a toda la fachada norte, ya que se observan respuestas similares en Asturias y Cantabria. ${ }^{21}$ No obstante, si algo caracteriza a este periodo es el aumento del brezal o monte bajo. Paralelo a la disminución del polen de roble y otros árboles que constituían el monte gallego, se detecta una mayor proliferación de especies de matorral: sobre todo de ericáceas (como la uz o Erica arborea L.), retamas y aulagas (tojos). ${ }^{22}$ Estas son especies clave del brezal atlántico y oromediterráneo, que aparentemente no tuvieron en este momento un gran uso por las poblaciones, ya que los estudios antracológicos sugieren que se seguía prefiriendo la madera de árboles, como los robles o fresnos, para calentarse..$^{23}$ Lo que sí probablemente sucedió fue un cambio en el paisaje del monte gallego, el cual ahora se vuelve más bajo y "pelado". Este clareo probablemente modificó la percepción del espacio, siendo posible abarcar mayores extensiones con la vista.

La transición entre el robledal y la combinación brezal-abedul no se puede interpretar como el resultado de un único factor, ya sea este natural o humano. Más bien, fue la consecuencia de una sinergia entre el deterioro climático y un aumento en la presión por parte de las gentes. Estudios en otro tipo de archivos ambientales, los suelos coluviales, revelan un nuevo factor ligado tradicionalmente en el noroeste peninsular al manejo del bosque, el uso del fuego. ${ }^{24}$ En las sierras del interior de Galicia, un trabajo con baja resolución para el periodo que nos interesa ha revelado un aumento en la intensidad de los fuegos en algún momento a partir del cambio de era. ${ }^{25}$ En suelos de Campo Lameiro (Pontevedra), una zona de media elevación, se observa una intensificación del régimen de incendios en torno al 500 (registrado como un

\footnotetext{
Muñoz Sobrino et alii 1997; Martínez Cortizas et alii 2005; Mighall et alii 2006; Silva-Sánchez et alii 2014.

Muñoz Sobrino et alii 2005.

Muñoz Sobrino et alii 1997; Santos et alii 2000.

Silva-Sánchez et alii 2014, los cambios de humedad se refieren a los índices reconstruidos en el propio testigo $\mathrm{y}$ variaciones regionales.

Mighall et alii 2006.

Para Asturias ver López-Merino et alii 2014; para Cantabria Jalut et alii 2010.

Muñoz Sobrino et alii 1997; Martínez Cortizas et alii 2005; Mighall et alii 2006.

Martín Seijo 2013.

Kaal et alii 2011.

Santos et alii 2000.
} 
aumento en el contenido en carbones ${ }^{26}$ paralelo a una mayor presencia de ericáceas, jaras, cereales y algunas herbáceas, ${ }^{27} \mathrm{y}$ al aumento de la erosión. ${ }^{28}$ Este hecho, unido a la presencia de llantén menor (Plantago lanceolata L.), especie típica de praderas, apunta según estos autores a un posible clareo del bosque para crear pastos..$^{29} \mathrm{En}$ las investigaciones realizadas en turberas también se ha detectado un aumento del polen de cereal y de esporas de hongos coprófilos que indican actividades agrícolas y ganaderas. ${ }^{30}$ Ambos hechos se unen a una acentuación en la erosión del suelo y una mayor presencia de carbones, ${ }^{31}$ así como de todas las especies de herbáceas, ${ }^{32}$ lo cual apunta en la misma dirección de intensificación de la ganadería y posible aumento de la agricultura después de la recuperación de los siglos IV y V. El estudio de suelos aterrazados llevado a cabo en las inmediaciones de Santiago de Compostela muestra la misma intensificación del uso del suelo entre el final del periodo romano y el siglo VI (hay un hiato en la cronología que no permite ser más exactos). ${ }^{33} \mathrm{El}$ aclarado muy posiblemente tuvo lugar mediante quemas controladas previas al aterrazamiento. En esta última zona también se documenta el uso de matorral bajo, como las aulagas (tojos), para la fertilización. El aterrazado intenso de Galicia parece haber tenido un origen en este periodo, intensificándose a partir del siglo V. ${ }^{34}$ Como nota, ha de recordarse que los suelos coluviales son archivos de baja resolución cronológica si se los compara con las turberas, por lo que, cuando se trabaja con estudios realizados en ellos, han de tomarse las fechas con más cautela. ${ }^{35}$

Además de la necesidad de pastos para la ganadería y nuevas tierras para la agricultura, el aumento de la presión humana sobre el bosque pudo estar condicionado también por el clima. ${ }^{36} \mathrm{El}$ observado empeoramiento de las condiciones climáticas, con inviernos más fríos, pudo incrementar la necesidad de "productos" del bosque en forma de leña. Estudios antracológicos de yacimientos arqueológicos romanos muestran un mayor consumo de madera de roble y de fresno para calentarse o cocinar. ${ }^{37}$ En Cova do Xato, en la sierra de O Courel, cueva que parece haber estado ocupada durante los periodos de inestabilidad climática de los siglos IV$\mathrm{V}$, se encontró una mezcla de maderas de combustión lenta, roble y retama, junto con otras de sauce o chopos para avivar el fuego. ${ }^{38}$ Por otro lado, cambios en las necesidades constructivas también influyen en la tala de árboles; el roble, el fresno

26 Kaal et alii 2008.

27 Carrión et alii 2010, 59, fig. 5 (diagrama), y 62; en el diagrama se aprecia el aumento de Erica sp, Erica arborea L. y Cistus.

28 Martínez Cortizas et alii 2009, 198, fig. 1, donde se puede ver la coincidencia de los momentos de mayor humedad obtenidos de Mighall et alii 2006 con el mayor contenido de carbones y erosión. El valor de $\mathrm{pH}$ disminuye volviéndose el suelo más ácido, alcanzando el valor mínimo de pH y por lo tanto el máximo de acidez, lo cual pudo cambiar la fertilidad de los suelos haciéndose necesario el uso de fertilizantes vegetales o del aterrazamiento.

$29 \quad$ Kaal et alii 2008; Kaal et alii 2011.

$30 \quad$ Silva-Sánchez et alii 2014.

31 Martínez Cortizas et alii 2005.

32 Mighall et alii 2006.

33 Ferro Vázquez et alii 2014; Ferro Vázquez et alii 2015; ver discusión sobre el uso de los suelos en la zona de Gaiás de Santiago de Compostela.

34 Ballesteros-Arias 2010, analiza 23 elementos del espacio agrario situados mayormente en Pontevedra y el norte de Lugo.

35 Variaciones en el entorno de las centurias, sin que se dejen de situarse en la Tardoantigüedad.

36 Los datos de los que dispongo no me permiten saber si es consecuencia de un incremento demográfico o no.

37 Martín Seijo 2013.

38 Teira Brión et alii 2012. 
y otras arbóreas se han encontrado en yacimientos del siglo III al V formando vigas, canalizaciones de aguas y hasta cestos. ${ }^{39}$ Un travesaño de madera de roble fue encontrado en Gijón (Asturias) como parte de un mecanismo para sacar agua de un pozo (cargadero), así como un cubo del mismo material. ${ }^{40}$ Otras actividades menos generalizadas en el espacio geográfico, como las salinas, también necesitaban árboles para su mantenimiento, tal y como se observa en Vigo, donde se halló un entretejido de castaño y otras maderas. ${ }^{41}$ Un último factor que se acopla a los periodos primero de recuperación del bosque y luego de caída de la cobertura arbórea, es la presencia de metales considerados contaminantes. En este caso, la deforestación y la erosión se asocian con las prácticas derivadas de la explotación de los metales (minería y metalurgia),${ }^{42}$ aspecto del que hablo en el siguiente apartado. En contra, las prácticas funerarias, y más en concreto la caída en desuso de la cremación, pudieron ayudar a la recuperación del bosque. La inhumación disminuye los requerimientos de madera, que se restringen a las cajas (normalmente de pino), mientras que en las cremaciones del noroeste se requerían grandes cantidades de roble, pino y fresno. ${ }^{43}$

Como herencia del periodo que estamos tratando, merece la pena reflexionar sobre lo que supuso la pérdida generalizada de los bosques en Galicia a partir del siglo VI. Esta caída fue tan profunda que no se observa retorno en los registros. Es decir, que el bosque nunca se recupera. Así, citando las palabras de Martínez Cortizas: "crea el paisaje gallego que conocemos", donde predomina el matorral tipo brezal. ${ }^{44}$ Por tanto, el periodo que nos atañe parece que constituyó el tránsito hacia una nueva realidad del paisaje arbustivo que tanto caracteriza esta zona de la Península Ibérica, siendo el actual una "herencia" fruto de las condiciones climáticas, sociales y culturales sucedidas desde el siglo IV. Para resaltar la importancia de estos cambios del paisaje vegetal del noroeste ibérico, valga mencionar que éstos se condensan en tres tipos de hábitats actualmente protegidos por la red Natura 2000: los brezales húmedos atlánticos de ericáceas, los brezales secos atlánticos costeros de ericáceas y los brezales oromediterráneos endémicos con aulagas (DOG Núm. 62, 31 de marzo de 2014). Los priscilianistas y sus coetáneos condicionaron en gran medida nuestra Galicia actual.

\section{Modificaciones en la explotación de los metales}

En la extracción y procesado de la mayoría de metales, como el oro, la plata, el cobre, el estaño, el mercurio o el plomo, se liberan a la atmósfera partículas (polvo generado en las operaciones mineras) y gases contaminantes (por liberación de vapores durante el procesado de las menas). En el caso del mercurio, además de su minería para usos directos, por ejemplo, en forma de minio como pintura roja,

39 Martín Seijo - Carrión Marco 2012; Martín Seijo 2013; Costa Vaz et alii 2016.

40 Ver Fernández Ochoa - Gil Sendino - Salido Domínguez 2015; Fernández Ochoa - Salido Domínguez - García Díaz - Gil Sendino 2015; Carrión Marco et alii 2015. Entre los restos de objetos de madera encontrados en el pozo-depósito de la fábrica de tabacos de Gijón muchos estaban realizados con roble y castaño, además de un gran cesto de madera de clemátide.

$41 \quad$ Martín Seijo 2013; Martín Seijo 2019.

42 Martínez Cortizas et alii 2005.

43 Aira Rodríguez - Uzquiano Ollero 1996; Martín Seijo 2013; Martín Seijo - Vila 2019.

44 Ver, por ejemplo, Martínez Cortizas et alii 2005; Martínez Cortizas et alii 2019. 
se usaba en la minería del oro. El mercurio servía para amalgamar el oro (unirse a partículas pequeñas) y posteriormente "refogar" la amalgama, es decir calentarla hasta alcanzar el punto de fusión del mercurio, el cual se volatiliza dejando el oro sólido. En el caso de la plata, esta está presente en minerales como la galena (sulfuro de plomo). Para su purificación se requería un proceso conocido como copelación o fundición en vaso de copela. Dentro de dicha copela se calentaba en ambiente aireado el mineral que contiene la plata causando la oxidación del plomo en forma de litargirio (monóxido de plomo). Este vaso separa la plata del litargirio a la vez que se libera parte de este monóxido en forma de vapores. Otro ejemplo es la producción de bronce, en la cual también se liberan vapores de estaño y cobre. En todos estos ejemplos los elementos metálicos como el plomo, el mercurio o el cobre pasaban a la atmósfera y se dispersaban a escala local, regional o hemisférica, llegando hasta Groenlandia, ${ }^{45}$ siendo depositados, por tanto, en la superficie terrestre en otro lugar. Al ser considerados metales tóxicos para muchos organismos, su presencia en la atmósfera se incluye dentro de la contaminación atmosférica. De hecho, la minería y la metalurgia fueron las dos principales actividades humanas causantes de contaminación atmosférica en el periodo preindustrial. La atmósfera no es en sí misma un archivo; no obstante, el hecho de que los metales fuesen depositados en diversas regiones del planeta ha permitido su estudio, reconstruyendo la contaminación atmosférica del pasado investigando registros de archivos naturales y bioarqueológicos (turberas, sedimentos de lagos, hielos polares, esqueletos humanos y animales), como veremos a continuación.

El periodo romano supuso un cambio radical en la intensidad de la minería y metalurgia. A partir del cambio de era, la alta demanda de productos metálicos por el Imperio trae como consecuencia un aumento de ambas actividades. El estudio de las turberas ha demostrado las consecuencias de ello. Tanto en Galicia como en otras áreas del suroeste de Europa, como los Pirineos, y en el norte de África, se observa un acoplamiento entre la deforestación del bosque, la erosión y el aumento de la contaminación por plomo, lo cual parece tener un origen común: la explotación de los metales. ${ }^{46}$ La contaminación viaja hasta el norte; en Fenoscandia se registran picos en la concentración de plomo en turberas y lagos. Se trata en estos casos de una contaminación que tiene su origen en el sur de Europa, ya que en Suecia la minería/metalurgia propia no alcanzó estas magnitudes hasta época plenomedieval. ${ }^{47}$ Este incremento en la contaminación atmosférica por metales es tan marcado en toda Europa y tan definido temporalmente, que el aumento del plomo en el periodo romano ha sido propuesto como un marcador cronológico en archivos ambientales. ${ }^{48}$

Las perturbaciones en el registro del plomo en los archivos naturales de las diversas regiones no son comparables en magnitud. Para el noroeste peninsular, desde los primeros estudios de metales contaminantes, como el plomo ${ }^{49} \mathrm{o}$ el mercurio ${ }^{50} \mathrm{se}$ observa un máximo preindustrial entre los siglos I y II. Diversos trabajos posteriores en turberas han detectado un pico similar de contaminación en este periodo en

\footnotetext{
Murozumi et alii 1969; Hong et alii 1996.

Martínez Cortizas et alii 2005.

Bindler 2011.

Renberg et alii 2001.

Martínez Cortizas et alii 1997.

Martínez Cortizas et alii 1999.
} 
Galicia y Asturias. ${ }^{51}$ Un estudio de isótopos de plomo pudo determinar que dicha contaminación procedía de minas del norte, noroeste y suroeste de España, pero no de otras áreas de Europa como Reino Unido, Italia, Austria o Grecia. ${ }^{52}$ Este aumento en el plomo y mercurio muestra en ocasiones efectos sinérgicos con el contenido en arsénico, níquel o cadmio, lo cual es indicativo de que la contaminación es polimetálica y sugiere la explotación de una mayor diversidad de fuentes y procesos minero-metalúrgicos. ${ }^{53}$ Los archivos naturales de Galicia también coinciden en mostrar un moderado descenso en la contaminación a finales del siglo III inicios del siglo IV, ${ }^{54}$ mientras que en Asturias este descenso se retrasa hasta finales del siglo V, cuestión esta última que se ha vinculado a la explotación de minas de esta región. ${ }^{55}$ A partir del siglo $\mathrm{V}$ se observa una caída importante en la contaminación metálica en todo el noroeste peninsular, ${ }^{56}$ que se desacopla por primera vez de la deforestación..$^{57}$

La explotación de los metales constituye una buena aproximación a la actividad humana en su vertiente más industrial, entendida esta por minería y metalurgia. Aunque la metalurgia puede ser desarrollada a pequeña escala para un uso familiar, lo cierto es que las grandes variaciones en su intensidad son probablemente una respuesta a la gestión socio-política de los recursos y no a decisiones individuales $\mathrm{o}$ al mero aumento de la población (ya que los metales no son recursos vitales). $\mathrm{Fe}$ de ello lo da la propiedad imperial de las minas en el mundo romano, que dependía directamente del emperador. ${ }^{58}$ Por ello, una caída de la actividad se podría relacionar con una menor estabilidad, lo que afectó a la explotación de estos lugares o la demanda de estos recursos. Es decir, que minería y metalurgia nutren principalmente a entidades supra-individuales, lo cual no deja de ser irónico cuando ahondamos en sus consecuencias.

La contaminación metálica tiene consecuencias importantes para la salud, incluso a bajas dosis, debido a la intolerancia del cuerpo a metales tóxicos como el plomo, el mercurio o el arsénico, que acaban incorporándose y causando problemas orgánicos o sistémicos, así como acrecentando las posibilidades de que otras enfermedades resulten fatales. Quizás se nos venga a la cabeza la idea de mineros o personas directamente relacionadas con el metal y tremendamente contaminados. No obstante, la más importante, a mi modo de ver, es aquella contaminación latente que estaba siendo incorporada por la población en general incluso en áreas muy alejadas. Pensemos que si los metales llegaban a las turberas situadas en lo alto de las montañas, éstos estaban en el aire, la comida y bebida de las gentes. Por lo tanto, esta contaminación crónica de relativamente baja entidad es la más extensa. Recientemente he propuesto que los esqueletos (humanos) arqueológicos sean

\footnotetext{
Ej. Martínez Cortizas et alii 2002a; Martínez Cortizas et alii 2002b; Martínez Cortizas et alii 2013.

Kylander et alii 2005.

53 Pontevedra-Pombal et alii 2013; en este artículo se indica la contaminación polimetálica, lo cual interpreto como la explotación de varias fuentes o recursos.

$54 \quad$ Kylander et alii 2005.

55 Martínez Cortizas et alii 2013.

56 Martínez Cortizas et alii 2002a; Martínez Cortizas et alii 2002b; Kylander et alii 2005; Martínez Cortizas et alii 2013; Pontevedra-Pombal et alii 2013.

57 López-Merino et alii 2014, los autores lo sitúan en torno al 440-700 y relacionan el menor descenso en la deforestación con un cambio en el uso de la tierra y una mayor dependencia del pastoreo en esta zona de montaña, pero no de prácticas agrícolas ya que el polen de cereal está ausente.

58 Zubiaurre Ibáñez 2017.
} 
considerados archivos ambientales al mismo nivel que otros de los que he hablado anteriormente, ya que registran y almacenan variaciones de su entorno. ${ }^{59}$

Uno de los aspectos a los que más pueden aportar es el estudio de la contaminación metálica. El registro de los cambios temporales y la validez de los esqueletos como archivos de la contaminación se demuestra en el trabajo que venimos haciendo en el yacimiento de A Lanzada (Sanxenxo, Pontevedra). Se trata de una población rural alejada de los grandes centros de minería, donde se han podido identificar dos áreas de enterramiento, una que cubre desde el siglo I hasta mediados del IV y otra que va del siglo IV al VII. En estos trabajos hemos demostrado cómo la contaminación por plomo y mercurio, incorporada en los individuos durante su vida, tiene una intensidad y huella isotópica similar a la registrada en otros archivos ambientales, con valores característicos de contaminación metálica relativamente intensa en el primer periodo y más bajos en el segundo. Los resultados coinciden a la perfección con la señal obtenida en las turberas de las que hemos hablado anteriormente. Además, en el caso del mercurio, se detectó un patrón intra-esquelético que sugiere que dicho metal estaba almacenado en los llamados órganos diana, entre ellos el hígado. Las investigaciones que estamos haciendo en estos momentos se encaminan a identificar mejor este patrón, así como a ampliar el número de estudios para esta región del noroeste. ${ }^{60}$ Estos trabajos nos enseñan que la contaminación llegaba a todas las poblaciones, así como que la caída de la actividad minero-metalúrgica durante la Tardoantigüedad dio lugar, probablemente, a una mejora de la salud de las personas (al menos en este aspecto).

\section{Una alimentación que se adapta}

La dieta en el noroeste de España parece presentar desde la Antigüedad unas características distintivas entre las que se incluye una dependencia del consumo de las denominadas plantas $\mathrm{C}_{4}$, que se remonta al Bronce Final, primeramente en forma de mijos y posteriormente de maíz. ${ }^{61}$ Los mijos son utilizados aquí directamente para el consumo humano. A su vez, y de acuerdo con los trabajos que hemos realizado, existe una marcada diferencia entre la alimentación de la costa y el interior, estando la primera caracterizada por un consumo extraordinariamente alto de productos marinos, ${ }^{62}$ mucho mayor que otras regiones europeas, costeras o no.

Una de las dificultades de la aproximación bioarqueológica a la alimentación de este periodo es cómo conocer los cambios en la dieta con respecto a los anteriores y posteriores, desechando variaciones locales. Es decir, para los objetivos que nos proponemos no resulta especialmente ilustrativo acercarnos a la alimentación de una

59 Oliva et alii 2018; López-Costas et alii 2020.

60 López-Costas et alii 2020, estudio de isótopos de plomo y concentración de plomo y mercurio; López-Costas et alii 2016, trabajo previo donde se diferencia la contaminación pre- y postmortem; Álvarez-Fernández et alii 2020, exploran la contaminación por mercurio en vida analizando diversos tipos de huesos. Esta metodología ha sido también aplicada a esqueletos de Suecia con idénticos buenos resultados.

61 Para la discusión de la introducción de los mijos ver López-Costas et alii 2015; estos corresponden a panizo, Setaria italica (L.) P.Beauv., y, sobre todo, mijo común, Panicum miliaceum L. Para la introducción del maíz en la alimentación humana y animal ver López-Costas - Müldner 2019.

62 López-Costas 2012; López-Costas - Müldner 2016; López-Costas - Müldner 2019, directamente en esqueletos humanos y huesos de animales, coincidentes para los recursos marinos con Grandal d'Anglade et alii 2015 y en el uso del mijo con Teira Brión 2019. 
zona muy concreta, así como tampoco el reconstruirla para un momento específico sin llegar a conocer si se trata de una preferencia de ese periodo o una continuidad del anterior. En el caso de los estudios de restos botánicos o animales contrasta la relativa abundancia de yacimientos de periodo romano, mientras que el número de aquellos que abarcan más allá del siglo IV decrece drásticamente. Un ejemplo de ello lo aporta la revisión de los trabajos de carpología, que incluye veintiún yacimientos para el noroeste de la Península entre los periodos romano y medieval, de los cuales solo uno tiene muestras adscribibles a los siglos V-VII.63 Estos estudios de semillas y otros para Galicia ${ }^{64}$ revelan el consumo de varios cereales en el noroeste "romano", tales como diversos trigos, avena, cebada, centeno y espelta. Esta última se mantiene en Galicia y en la montaña asturiana, pero desaparece de los yacimientos tardoantiguos y medievales de toda la Península. Se encuentran también sobradas evidencias de mijos, mijo común y panizo, importantes en la economía del noroeste donde constituyen el 30\% de las semillas recuperadas (siendo de solo un 3\% en otras áreas). Al menos para Asturias, parece que la espelta y otros tipos de escandas son predominantes en aquellas zonas que por su humedad y bajas temperaturas hacen difícil el cultivo de los mijos. ${ }^{65}$ La escasa variedad de legumbres, habas (en concreto Vicia faba L.), arvejas (Vicia sativa L.) y guisantes, contrasta con la del resto de la Península Ibérica. Otros alimentos vegetales encontrados en el noroeste incluyen castañas, nueces, avellanas, piñones, manzanas, cerezas, uvas, higos, aceitunas o nabos. En proporción, lo que más destaca son los cereales. No existen, por tanto, grandes diferencias que nos permitan hablar de un tipo de cultivos característicos de la Tardoantigüedad, aunque el consumo de cebada sí parece haber aumentado a partir del siglo IV. En relación con otras áreas peninsulares, en el noroeste destaca la importancia relativa que tuvieron los mijos, la cebada y la espelta, mientras que el centeno no despuntó hasta el periodo medieval. ${ }^{66}$ Semillas de ciruelas, melocotones, pepinos o melones fueron identificadas en un puerto costero de la actual ciudad de Vigo, por lo que pueden ser un reflejo del tráfico marítimo y no haber estado disponibles para toda la población. ${ }^{67}$ Incluso en las áreas habitacionales de nueva construcción dedicadas a explotaciones concretas, como la minería en la zona de Las Médulas (El Bierzo, León), se hallaron trigo, cebada, mijo y habas. ${ }^{68}$ Con respecto a la comida "ritualizada", no tenemos evidencias de restos vegetales para el periodo estudiado, pero se han hallado guisantes, habas, lentejas y huesos de animales en piras funerarias del siglo I en el norte de Portugal, lo cual se relaciona con el ritual

63 Peña-Chocarro et alii 2019 , analizan un total de 252 muestras $(\sim 1 / 5$ del total para todos los periodos, todas las áreas), que son adscribibles cronológicamente a los siglos II y VII, la mayoría de contextos rurales. Existen, no obstante, 11 yacimientos que tienen alguna fase entre los siglos IV al VI.

64 Condensados en la tesis Teira Brión 2019.

65 Ver discusión sobre la convivencia entre mijos (verano) y escanda (invierno) y las grandes áreas dedicadas al cultivo de esta última en la montaña asturiana (Vigaña) en Fernández Mier 1999, 268. Ver también Fernández Mier 2013.

66 Peña-Chocarro et alii 2019.

67 La abundancia de restos carpológicos de frutas exóticas en el depósito anegado de las salinas de Vigo -Teira Brión 2013- contrasta por ejemplo con la escasez de restos carpológicos de importancia económica de otros registros más alejados de zonas de tráfico marítimo como el pozo-depósito Tardoantiguo (siglos VI-VIII) de la fábrica de tabacos de Gijón, ver Carrión Marco et alii 2015.

68 López-Merino et alii 2010, referido a los trabajos realizados en el yacimiento romano de Castro de Orellán, figs. 6 y 11 . El trigo se refiere aquí a trigo farro (Triticum dicoccum L.). 
funerario. ${ }^{69} \mathrm{~A}$ mi conocimiento, no existen hallazgos similares o huesos de animales atribuibles a este uso en ninguna de las inhumaciones de Galicia, aunque sí se han encontrado ajuares cerámicos. ${ }^{70}$

Con respecto a la cabaña ganadera, el periodo romano no parece suponer en esta región un cambio drástico en las especies, dominando el ganado caprino (ovejas y cabras) mientras que el vacuno parece ser más frecuente en la zona cantábrica, siendo los cerdos menos frecuentes. Esta continuidad también se observa en el suroeste peninsular, aunque la caza del ciervo parece ser una actividad más importante aquí. ${ }^{71}$ En las zonas urbanas o aquellas más romanizadas de nueva planta, el ganado porcino adquiere una mayor importancia, llamando la atención los huesos de cochinillos, de aves (gallinas y gansos) y de caza. ${ }^{72}$ Destacan también hallazgos puntuales de camélidos (dromedarios) en estratos tardíos de Astorga. ${ }^{73}$ La cabaña ganadera del noroeste sufre también transformaciones en cuanto a los morfotipos, que se vuelven ahora más grandes y con mayor aprovechamiento de carne, aunque se mantienen los animales de menor tamaño típicos de la Edad de Hierro. También aparecen nuevos tipos de caballo y perros pequeños asociados al ámbito doméstico de las clases pudientes. Teniendo en cuenta el volumen, el ganado vacuno parece ser el que proporcionaba mayor cantidad de carne a la dieta, aunque el caprino posiblemente aumentó a partir del siglo IV. ${ }^{74}$ Sin embargo, la escasez de yacimientos pertenecientes a la Tardoantigüedad no nos permite conocer si hubo modificaciones severas en el tipo de cabañas ganaderas ni en su tamaño corporal, tal y como se constató en otras áreas del norte peninsular. ${ }^{75}$

En el mundo romano, con respecto a la Edad de Hierro, se observan ligeros cambios en la pesca, ya que las artes introducidas facultan la captura de especies de fondo y bancos de jureles o sardinas en mar abierto. Aumentaron y se diversificaron las fábricas de salazón, ya presentes en el periodo anterior, aunque ahora se procesan especies como la sardina, posibilitando la llegada de productos marinos elaborados hasta las zonas interiores. ${ }^{76}$ Los peces más representados son la sardina, la dorada, la maragota y el jurel, aumenta la presencia de abadejo y merluza, y decrecen en importancia la faneca y el besugo. ${ }^{77}$ Se han encontrado restos de erizos y ostras en localidades del interior, como Astorga. Existió una distribución de los moluscos en

69 Vaz et alii 2020; las legumbres tienen marcas compatibles con haber sido cocidas, sin embargo, otros cereales están ausentes aquí. Los huesos de animales no pudieron ser identificados salvo un fragmento de radio de cerdo joven $(<4$ años).

70 Se han encontrado ajuares cerámicos en tumbas claramente adscribibles al siglo IV en Asturias (Requejo Pagés 2015) y posiblemente adscribibles a la primera mitad de este siglo en A Lanzada (López-Costas 2015; LópezCostas et alii 2020).

71 Valenzuela-Lamas - Detry 2017; estas autoras encuentran también un paulatino aumento en el tamaño de los cerdos y una gran diversidad de prácticas ganaderas, aunque ha de tenerse en cuenta la gran amplitud de la región estudiada en este trabajo.

72 Rodríguez 2000; Fernández Rodríguez 2003; Fernández Rodríguez - Fuertes Prieto 2007; se pueden encontrar buenas revisiones en estos trabajos para el Noroeste de España.

73 Fernández Rodríguez - Fuertes Prieto 2007.

74 Fernández Rodríguez - Fuertes Prieto 2007.

75 Grau-Sologestoa 2015, quien ha estudiado la biometría de cabras-ovejas, vacas y cerdos, encontrando una reducción del tamaño de cerdos y cabras-ovejas en la Tardoantigüedad, sin que se vea afectado el tamaño de las vacas hasta el siglo VIII.

76 Rodríguez Martínez et alii 2011, documentan una de estas explotaciones prerromanas en A Lanzada (Sanxenxo, Pontevedra). Para periodo romano destaca el yacimiento de Adro Vello (O Grove, Pontevedra) donde se encontraron seis piletas de salazón con vértebras y escamas de sardina y jureles (Ferré Álvarez 2003).

77 González Gómez de Agüero 2013, 355-357, para la ictiofauna. 
los periodos Alto y Bajoimperial (hasta el siglo V), los de roca en los asentamientos costeros y los bivalvos de arena en el interior, incluyendo grandes ciudades como Lugo o Astorga. En estas aparecen también abundantes restos de ostras y vieiras, fiel retrato de un comercio de recursos marinos destinado muy posiblemente a las élites. ${ }^{78}$

Un elemento necesario para la realización de salsas y salazones es la sal, que adquiere importancia industrial en el sur de la actual Galicia a partir del siglo I. Estudios realizados en salinas de la zona de Vigo, área intensamente explotada desde el cambio de era, indican el desuso de la mismas a partir del siglo V y hasta el VII, ${ }^{79}$ relacionado con modificaciones en las corrientes y dinámica de la ría. Los estudios bioarqueológicos no permiten ir más allá de este ejemplo concreto. Lo mismo sucede con otros productos, los diversos autores asumen un cambio, si no en las especies, sí en la intensidad de su explotación, relacionado con la pérdida de estructura comercial que parece que sigue al siglo IV; sin embargo, todos resaltan la falta de yacimientos. Hemos de indicar aquí que los estudios arqueobotánicos y zooarqueológicos son importantísimos para conocer la dieta a nivel poblacional, aunque no es posible conocerla para una persona o grupo concreto. Además, en estos casos tenemos que ser conscientes de que las condiciones de conservación pueden generar sesgos interpretativos. Es decir, el hecho de que la mayoría de los materiales botánicos estudiados estén conservados por carbonización, y muchos menos por saturación de agua, podría causar la sobrerrepresentación de aquellas semillas o maderas con más posibilidades de tener contacto con el fuego y no ser calcinadas, sino carbonizadas. En el caso de los restos animales, y al igual que los humanos, normalmente llegan a nosotros solo los esqueletos (incluyendo conchas).

Un modo directo de reconstruir la dieta en el pasado lo proporciona el análisis de los restos óseos humanos empleando metodologías como la patología oral o los análisis de isótopos estables en hueso y diente. Galicia destaca por la abundancia de estudios de isótopos estables, los cuales nos permiten aproximarnos a la alimentación de hombres, mujeres y niños por separado, o enlazar esta información con otra para asumir el estrato social. Los estudios de isótopos estables para la reconstrucción de la dieta han revelado un alto consumo de mijos tanto en el interior (yacimiento de Ouvigo, Os Blancos, Ourense) como en la costa (yacimientos de A Lanzada, O Grove, Pontevedra; y Calle Real, A Coruña) ${ }^{80}$ Estos mijos no eran usados como forraje del ganado, como sucede en otras áreas peninsulares, sino consumidos directamente por las personas. Los yacimientos costeros muestran un característico patrón de moderado-alto consumo de recursos marinos. A partir del siglo IV el consumo de recursos marinos y mijos aumenta considerablemente, constituyendo probablemente la base de la dieta. Este cambio de patrón ha sido observado en la necrópolis de A Lanzada, cuyas características únicas de contar con dos áreas funerarias me permiten profundizar sobre cómo cambió la alimentación en una misma área. Para Galicia, hemos observado también un aumento similar o incluso mayor del consumo de recursos marinos y mijo (o incluso maíz) durante periodos posteriores de deterioro

78 Bejea García 2015, 570-577, para la malacofauna mencionada.

79 Tallón-Armada et alii 2018.

80 López-Costas 2012; Silva-Sánchez et alii 2013, datos de los esqueletos romanos de Ouvigo (siglos II-IV). López-Costas - Müldner 2016, para la reconstrucción de la dieta de A Lanzada. Grandal d'Anglade et alii 2015 y Kaal et alii 2016 para la Calle Real de A Coruña. 
climático como la Pequeña Edad del Hielo. ${ }^{81}$ Una mayor dependencia de los mijos en la alimentación humana y animal se detectó en otros yacimientos europeos, $\mathrm{y}$ en todos los casos lo hemos asociado a un empeoramiento de las condiciones climáticas a partir del siglo IV, que podrían haber dificultado el cultivo de otros cereales, así como todas las características de cambios ambientales y sociales, y los movimientos de población. ${ }^{82}$ Las modificaciones en la alimentación de A Lanzada no coinciden con un tipo de tumba o ajuar concreto de los enterramientos, y tampoco ha podido identificarse ningún elemento que ayude a la adscripción religiosa de ningún individuo. Hemos propuesto, incluso, que dichos cambios pudieron estar promovidos de alguna manera por la llegada de los grupos germánicos, ya que los mijos eran consumidos en la zona actualmente ocupada por Alemania. Sin embargo, los estudios isotópicos y carpológicos nos hablan de que dichos cultivos eran de sobra conocidos y empleados en el noroeste peninsular desde al menos el Bronce Final. Es, por tanto, difícil conocer si el cambio de alimentación hacia una mayor dependencia del mar y de las plantas $\mathrm{C}_{4}$ se debe a un condicionamiento externo ambiental, principalmente social o a una combinación de ambos. Con seguridad, las futuras investigaciones sobre otras necrópolis de esta área, así como sobre la alimentación infantil, nos ayudarán a ahondar en estos interrogantes.

\section{Breves apuntes sobre la morfología, salud, enfermedad y costumbres funerarias}

El examen de otros aspectos de la vida y muerte de los individuos, así como si estas cambiaron a partir del siglo IV, depende del análisis directo de los restos esqueléticos humanos, no especialmente abundantes en esta región. ${ }^{83}$ Sin embargo, estos estudios son dependientes de un buen tamaño muestral ya que se requiere de una mayor interpretación a nivel poblacional. ${ }^{84}$ Esto no quiere decir que en los casos anteriores de reconstrucción de la dieta y de la contaminación la perspectiva poblacional no sea necesaria, ni que en estos últimos el estudio de individuos o grupos pequeños no tenga importancia. Cuando se trabaja con la llamada geoquímica del esqueleto (ej. dieta por isótopos estables) es posible obtener un dato de cada uno de los esqueletos casi independientemente de cómo de completo esté el mismo. En cambio, en otros trabajos, como la antropometría, la paleopatología o la tafonomía, se hace necesario que una determinada pieza esté completa, si no todo el esqueleto, reduciendo la cohorte de individuos que se pueden estudiar. Por ello, la fortaleza de las conclusiones que se extraen muchas veces es limitada.

Nos vamos de nuevo al yacimiento de A Lanzada, donde no se han observado grandes diferencias en el morfotipo y antropometría entre los esqueletos recuperados en las áreas funerarias romana (siglos I-IV) y tardoantigua (siglos IV-VII). Las

81 Oliva et alii 2018; López-Costas - Müldner 2019; definimos la Pequeña Edad de Hielo como el periodo del 1300 al 1850 .

82 López-Costas - Müldner 2016; discutimos estos aspectos, por ejemplo para Alemania Hakenbeck et alii 2010. Posteriormente Jordana et alii 2019 retoman esta cuestión observando un ligero aumento para Cataluña. Debate sobre el uso de mijos en la Península Ibérica en López-Costas - Alexander 2019.

83 Solo siete yacimientos con esqueletos estudiados se pueden adscribir a los siglos estudiados; para un resumen de estudios de osteoarqueología en época medieval para Galicia consultar López-Costas - Sánchez Pardo 2016, en concreto la figura 2.1 y la tabla 2.1 .

84 Para caracterizar una población (estadística), entendida esta aquí como una cohorte de individuos que comparten características, ha de analizarse un número de muestras representativo de la misma. 
estaturas, tanto de la serie femenina como de la masculina, son similares, dando en su conjunto una media de $157 \pm 5 \mathrm{~cm}$ y $165 \pm 5 \mathrm{~cm}$, respectivamente..$^{85}$ Ha de tenerse en cuenta que si quisiésemos comparar estos individuos con otras poblaciones deberíamos emplear los valores estimados de estatura, evitando contrastar las medidas concretas de un hueso. ${ }^{86}$ Las estaturas estimadas en A Lanzada son mediaaltas para los hombres y altas en las mujeres cuando se comparan con las de otras poblaciones de la Península. Debido a la elevada estatura media de estas últimas, el dimorfismo sexual no es muy acusado. Un bajo dimorfismo sexual se relaciona con malas condiciones de vida, ya que ambos sexos estarían sometidos a un fuerte estrés en la infancia, lo cual no les permitiría alcanzar la estatura potencial máxima. En un análisis de diversas poblaciones peninsulares se observa un aumento en la robustez y la estatura media en el periodo romano y tardoantiguo, hecho también observado en Galicia ${ }^{87}$ Sin embargo, el hecho de que ambas series de A Lanzada tengan valores supra-medios con respecto a otras series españolas, hace que no nos podamos decantar por esta hipótesis basada en el dimorfismo sexual. ${ }^{88}$

En base al estudio paleopatológico de los esqueletos arqueológicos datados entre los siglos IV y VII sabemos que esta población estaba en contacto con enfermedades infecciosas bacterianas, como la tuberculosis y la brucelosis. He hallado marcas compatibles con dos posibles casos crónicos de tuberculosis y otros dos de brucelosis en la segunda fase de A Lanzada ${ }^{89}$ pero ninguna en la primera ya que en su excavación no se recogieron los huesos cortos y las marcas patognomónicas de ambas patologías se encuentran en la columna vertebral..$^{90}$ Estas patologías dejan marca en el esqueleto solo en los casos crónicos, por lo que no es de extrañar que los diagnosticados conviviesen con bastantes más casos agudos, hecho que sugiere una extensión importante de ambas enfermedades en la población. Estas enfermedades estaban también presentes en otras poblaciones del periodo de la Península y no parece existir un aumento en la Tardoantigüedad. ${ }^{91}$ Aunque algunos autores han sugerido la existencia de una "involución" en las prácticas médicas de este periodo con respecto a la época clásica, no se han encontrado evidencias claras para Galicia. ${ }^{92}$

Finalmente, muchos de estos cambios se reflejan tanto en la vida como en la muerte. En un trabajo sobre la arqueología funeraria de las dos fases de A Lanzada se determinó que la fase romana se caracteriza por una orientación de las tumbas Norte-Sur y Sur-Norte, ajuar y enterramientos con ropa. Se incluyen también en esta fase cremaciones (excavadas, pero no recogidas) y enterramientos en decubito prono con el cuerpo depositado con poco cuidado y, en un caso, posiblemente

85 López-Costas 2012, 197. Las series están compuestas por 10 muestras en cada caso. Estimación realizada en base a Pearson 1899 .

86 En población viva se observa que personas con la misma estatura tienen medidas óseas diferentes (por ejemplo, de la longitud máxima del fémur) dependiendo de aspectos como el ángulo de inserción en la cadera, las cuales se pueden estimar de manera bastante aceptable si empleamos fórmulas que atiendan a estas variaciones a nivel poblacional. Un ejemplo de lo que creo que es un mal uso metodológico, donde se han comparado medidas concretas en vez de la estimación de la estatura empleando las fórmulas específicas de cada población, se puede observar en Harper 2017, 75-78.

87 Estudio biométrico realizado por Jordana - Malgosa 2004; ver también discusión en Menéndez Bueyes 2013, 124, basado sobre todo en la tesis de Varela López 1974-75. Para Galicia véase López-Costas et alii 2007.

88 López-Costas 2012, 201-203, comparación con 22 poblaciones de entre los siglos I al XVIII.

89 López-Costas 2012.

90 Aufderheide - Rodríguez-Martín 1998.

91 Menéndez Bueyes 2013, 91-96; Menéndez Bueyes 2016.

92 Menéndez Bueyes 2013, 119. 
maniatado. Los enterramientos presentan piezas constructivas de barro cocido como tégulas o ímbrices, o se hicieron directamente sobre el terreno. En la segunda área, la tardoantigua, el ajuar desaparece por completo, así como los restos arqueológicos que sugieran piezas de vestir o calzado. La orientación cambia a un estricto Oeste-Este y se ha anotado la presencia de conchas cerca de los cuerpos, aunque nuestras últimas intervenciones en el yacimiento nos hacen pensar que pudiesen ser depósitos casuales ya que la necrópolis está en una duna. ${ }^{93}$ La posición de los cuerpos es en decubito supino y aparecen enterramientos múltiples no consecutivos en tumbas de lajas de piedra, lo cual indica la reutilización de las mismas. Una reutilización similar la hemos observado en una reciente excavación en la calle Oliva de Vigo, en una de las pocas tumbas adscribibles estratigráficamente a la Antigüedad Tardía. ${ }^{94}$ En el caso de los individuos colocados boca abajo del periodo imperial, la falta de ajuar y el hecho de que se depositaran en un área funeraria al lado de otros que muestran una posición no desviada no nos permite determinar si existió una actitud punitiva o de rechazo; las características antropológicas tampoco proporcionan información de si se trataba de personas libres o esclavas. En la segunda fase encontramos un esqueleto cuyos huesos del pie muestran marcas de mordiscos de un cánido en hueso fresco, este tratamiento descuidado podría asociarse a un mismo fenómeno de enterramientos depositados en áreas anómalas a partir del siglo $\mathrm{V}$ en Cataluña, ${ }^{95}$ o ser un hallazgo puntual. Hasta donde conozco no hay casos similares descritos, lo cual también puede deberse a falta de estudios detallados sobre marcas tafonómicas. Finalmente, he discutido la posible adscripción de estas prácticas funerarias a un cambio de creencia, como la llegada del cristianismo, ${ }^{96}$ por ejemplo, sin haber encontrado evidencias claras, por lo que dejaré esta discusión a otros que puedan llevarla más allá de la evidencia material a la que me acojo. Evidentemente, no es posible determinar la adscripción religiosa de las personas inhumadas en este periodo, ni el registro bioaqueológico nos permite conocer sus vínculos, puramente hipotéticos, con el priscilianismo.

\section{La vida en tiempos de Prisciliano y de los priscilianistas, una reflexión}

Los priscilianistas y sus coetáneos vivieron en una Galicia surcada por profundas modificaciones. Reducirlas aquí a un único factor, el cambio religioso, sería una

93 En las primeras excavaciones (Blanco Freijeiro et alii 1967) se indica la presencia de conchas, de berberecho, almeja y en un caso de vieira, en las tumbas 16, 18, 19, 22, 23 y 30, estas son identificadas como parte del ajuar. Aparecen cerca de diversas zonas del esqueleto (entre las piernas, al lado de un brazo, de una pierna, cerca de la cabeza) y algunas son ejemplares no completos. Una consulta de las fotografías de la intervención (es difícil adscribirlas a una tumba concreta; véase López-Costas 2015) no revela una intencionalidad ni protocolización en la colocación de dichas conchas, y estas aparecen en las tumbas excavadas en la duna, no en las realizadas en otros suelos. En la intervención de 2016-2017 observamos la presencia de conchas de especies similares en la arena de la duna, fuera y dentro de los enterramientos, por lo que parece poco probable que se trate de un ajuar, sino más bien de depósitos no intencionales relacionados con el material de partida donde se realizó el enterramiento. Habría que revisar otros yacimientos costeros para poder ahondar en las sobreinterpretaciones de este tipo de hallazgos.

94 López-Costas 2015, para la arqueología funeraria en contexto con el estudio de los restos humanos. El estudio de la calle Oliva está en curso.

95 López-Costas 2015, para la descripción de los enterramientos fuera de norma en A Lanzada. Olesti Vila 2019, expone un interesante resumen de los esqueletos hallados en áreas no funerarias o en posiciones anómalas en el noreste peninsular.

96 López-Costas - Müldner 2016. 
gran simplificación, tal y como he querido mostrar en las líneas anteriores. Es muy posible que las gentes se vieran condicionadas por la inestabilidad derivada de la imposición de una nueva élite que parece haber convivido de manera agitada con la vieja, pero que también pacta con ella tal y como demuestra la paz firmada en el año 433 entre los suevos y los Gallaeci. ${ }^{97}$ Sin embargo, ¿cómo podemos ignorar la realidad que impuso el clima? Sin caer en un determinismo ambiental simplista, se debe admitir que el empeoramiento de las condiciones de humedad y temperatura sin duda condicionó la vida de las gentes del campo, así como la selección de los cultivos más apropiados, de entre los que se conocían en el mundo romano. En este caso no intento imponer una visión de crisis total ni negar la opulencia de los grandes terratenientes del siglo IV. ${ }^{98} \mathrm{Mi}$ intención es dejar patente que las condiciones de vida se pudieron ver alteradas por los cambios ambientales, especialmente las de las clases más humildes, sin caer en un catastrofismo ambiental. Dicho esto, los tiempos manejados por los archivos ambientales no se ajustan a la vida de una generación de personas, por lo que quizás las modificaciones climáticas que parecen cruciales a escala de centurias no tuviesen un impacto definitivo en las vidas individuales (aunque sí no ignorable).

Un aspecto sobre el que me gustaría reflexionar aquí, pues ha sido uno de los principales focos de mi investigación en los últimos años, es el del papel jugado por los mijos. Este tipo de cultivos, conocidos como cereales de primavera, se puede plantar a finales de esta estación o en verano, recogiendo el grano en un par de meses. Resultan una opción ideal si se quiere dedicar los terrenos a pasto el resto del año, o como contrapunto al más delicado trigo o a otros cereales de invierno como la cebada. La resistente espelta también puede ser una buena opción ante el empeoramiento climático, tal y como constatan los estudios realizados en la montaña asturiana. Son, por lo tanto, los mijos y la espelta, combinados con la ganadería en el interior y los recursos marinos en la costa, buenas opciones para momentos de inestabilidad/cambio social y ambiental. Su aumento entre los siglos IV y VI está, creo yo, vinculado a esos cambios. Si esta modificación en las preferencias se relaciona con las nuevas creencias es difícil de decir; quizás el hecho de que ambos sucedieran a la vez proporcionó un contexto doctrinal a la nueva realidad que cada vez se alejaba más del utópico mundo romano, como tanto nos recuerda Hidacio.

Las fuentes documentales y las bioarqueológicas difieren en que las primeras se centran en asuntos puntuales de marcado impacto social, mientras que las otras nos hablan de aquellos aspectos que formaban parte del día a día. En nuestros estudios no hemos hallado evidencias ni de violencia interpersonal ni de pestes. El saqueo y las masacres sucedidas en ciudades como Asturica Augusta o Bracara Augusta ${ }^{99}$ no tienen un reflejo en los restos óseos; si bien es verdad que estos eventos que crean gran alarma social (como el asesinato de un obispo en su iglesia) ${ }^{100}$ no tuvieron por qué extenderse a toda la población ni mucho menos llegar a zonas rurales como las

\footnotetext{
97 Hyd. Chron. 100; López Barja de Quiroga 1999.

98 Brown 2012.

99 Hyd. Chron. 183 (Asturica Augusta), 167 y 173 (Bracara Augusta); Burgess 1989, 150: hambre y episodios de canibalismo en las ciudades saqueadas. Candelas Colodrón 2004, 245 y 247, para el saqueo de Braga y para la destrucción de Astorga y de sus campos de cultivo, respectivamente.

100 Hyd. Chron. 141, con Burgess 1989, 219: Leo obispo de Tyriasso en 449.
} 
estudiadas. Las pestes mencionadas por Hidacio, ${ }^{101}$ las cuales son golpes previos a la gran peste de Justiniano (541-549), no tienen un reflejo en el registro óseo. Tampoco lo tienen otros eventos como los terremotos de los años 451 y $454 .{ }^{102}$ No es esperable que lo tuviesen ya que, de causar muertes, la rapidez de ambos fenómenos impide la formación de marcas en los esqueletos, restringiéndose las evidencias a la presencia de fosas comunes, las cuales, de existir, no han sido aún descubiertas. Podrían ser evidencias sutiles el descuido en el cuidado del cuerpo de los difuntos observado ocasionalmente en A Lanzada y otras áreas de la Península, el cual sí se puede relacionar con la inmediatez, así como con grupos en movimiento o muertes que sucedieron de manera imprevista.

Se ha debatido sobre el catastrofismo en la obra de Hidacio asumiendo que adquiere un grado de irrealidad importante. Según algunos autores a partir de un momento en que la Chronica versa sobre "la destrucción total del Reino Suevo de la Gallaecia"103 este discurso se vuelve tan alejado de la realidad que "podemos eliminar la reconstrucción histórica que se refiere a la destrucción de las ciudades". Dicho supuesto se basa principalmente en la mención a la presencia de camellos durante la destrucción de Bracara como parte del ejército de los godos. ${ }^{104}$ En concreto, Javier Arce indica que, en su opinión, "estos camellos nunca existieron", pues lo ve como algo imposible y una exageración del cronista, y en ello basa su argumentación de catastrofismo irreal. No obstante, los estudios bioarqueológicos han revelado la existencia de huesos de camélidos (dromedarios) en Astorga coincidentes con el periodo narrado. ${ }^{105}$ Carlos Fernández Rodríguez y Natividad Fuertes Prieto hacen una excelente descripción de dichos hallazgos. Dicho esto, no cabe duda de que Javier Arce tiene razón cuando señala que el siglo $\mathrm{V}$ fue "un siglo en transición de unas estructuras políticas, administrativas, económicas, una concepción de la vida de la ciudad y de creencias religiosas, pero marcadas en muchos aspectos por la continuidad". ${ }^{106}$ En este sentido apunta también la información bioarqueológica. Pero, a su vez, sí creo que hubo momentos puntuales de caos y destrucción, los cuales se vieron magnificados en la vida de la gente que los sufrió y dejaron un impacto en una Chronica que quizás no es tan irreal como pensamos, al menos en lo que se refiere a la presencia de camélidos en la Gallaecia.

La posible inestabilidad puntual concuerda con el uso de las cuevas como zona habitacional provisional y una vuelta a la ocupación de áreas elevadas que proporcionan buen refugio. Es posible, entonces, que el descenso de la cobertura arbórea después de la ligera recuperación del siglo IV se relacione con esta nueva manera de vivir en respuesta a la inseguridad puntual de los grandes

101 Hyd. Chron. 126; Burgess 1989, tabla 4.

102 Burgess 1989, tabla 4.

103 Cita literal de Arce 1995, 219, quien expresa su incredulidad sobre la crónica de Hidacio en base a la presencia de camellos en la Gallaecia. Esta cita ha sido usada por autores como Díaz (2000) o Candelas Colodrón (2004), entre otros muchos, para justificar la visión irreal y catastrófica dada en la Chronica.

104 Literalmente: iumentorum, pecorum, camellorumque horrore locus sacer impletus (Hyd. Chron. 174); Burgess 1989. Esto es interpretado por Arce 1995, como que estos animales forman parte del ejército del rey godo Teodorico, sin embargo lo que se indica en la crónica es que estos animales entraron en el lugar sagrado (locus sacer impletus) sin especificar si pertenecían o no a dicho ejército.

105 Estos hallazgos se explican en Fernández Rodríguez - Fuertes Prieto 2007, señalando que se trata de un periodo tardío (con respecto al periodo romano) y que posiblemente se relacionen con movimientos de tropas, quizás desde el Norte de África o empleados para el comercio y carga de bienes.

106 Reflexiones incluidas en Arce 2013, 281-284. 
núcleos de población. Las gentes trasladan la agricultura, pero sobre todo la ganadería, a estas zonas para subsistir, mientras que la minero-metalurgia ya no es una actividad esencial del día a día. Hechos que tendrían como consecuencia el observado desacoplamiento de la contaminación metálica y la deforestación. Los robledales probablemente tuvieron que acoger a las gentes que se trasladan de los núcleos más poblados, movimiento quizás alentado por las hambrunas de las que habla Hidacio, como la que siguió a la entrada en Hispania de los suevos, vándalos y alanos. ${ }^{107}$ No podría asegurar si estos movimientos responden a un aumento de la fe eremítica, pero de ser así constituirían seguramente una buena manera de "ganarse el pan" en este periodo. A la vez, estos modos de vida podrían ser el germen de los cenobios, que tan intensamente popularizaría San Fructuoso de Braga en la Gallaecia.

La información bioarqueológica indica un cierto aumento de la presión antrópica sobre el medio a partir del siglo V, después de la caída del siglo IV. Si esto constituye un aumento de la actividad o un crecimiento económico a nivel de toda Galicia es un interesante debate al cual aún no podemos aportar suficientes datos. Además, ¿cómo podríamos explicar la escasez de yacimientos de esta cronología que los autores que he citado indican? ${ }^{108}$ Por otro lado, quizás estos hechos estén relacionados con un aumento de la producción autosuficiente y la economía autárquica que se vuelve más familiar asociada al retraimiento económico y a una nueva manera de producir, ${ }^{109}$ que, creo yo, pudiesen resultar más adecuadas a las nuevas condiciones ambientales. Lo que sí parece claro es que el tipo de actividades cambió siendo la mayor explotación del bosque y superficie de prados aspectos clave. Aparece una nueva manera de vivir que pudiera estar mejor adaptada a un peor clima y al aumento de la erosión intensificada por un desbroce incontrolado, de ahí los sistemas de terrazas. No se puede interpretar esto directamente como un aumento demográfico, ya que el impacto antrópico sobre el medio no depende del número de habitantes sino de las actividades que éstos desarrollan. Quizás esta nueva realidad se adapte mejor a la existencia de unas nuevas élites locales que ya no dependían de Roma, pero sus características son difíciles de abordar desde este tipo de estudios. La bioarqueología nos va a hablar más del conjunto de la población, y muy rara vez de las personas que ostentaban el poder.

Finalmente, los priscilianistas de esta región, así como sus congéneres, posiblemente se enfrentaron a una modificación de las condiciones socioambientales que pudieron causar, hasta cierto punto, una ruptura en la resiliencia de su entorno y formas de vida. Su legado se puede ver no solo en las costumbres funerarias, sino también en los complejos sistemas de terrazas o socalcos, y en los brezales, todos ellos tan característicos del paisaje gallego actual. Animo aquí a que otros investigadores empleen esta información para abordar aspectos diferentes de la historia social y económica, y juntos podamos añadir nuevas perspectivas al conocimiento que tenemos de estos siglos.

107 Hyd. Chron. 48; Burgess 1989, 91, se refiere al hambre y enfermedad del ganado, quizás pudiésemos relacionarlo con la brucelosis, enfermedad eminentemente del ganado que afecta también a los humanos.

108 Pudiendo tratarse también de malas asignaciones cronológicas.

109 Sobre la reflexión del cambio en la economía y la productividad Arce 2013, 275-279. Brown 2012, 139-162 incide también en la importancia de las élites locales cada vez más alejadas de Roma. Nótese que en estos trabajos el uso de la información bioarqueológica es prácticamente nulo, por ejemplo buscando referencias concretas al tipo de ganado consumido en la Chronica de Hidacio antes que en los estudios zooarqueológicos Arce 2013, 276. 


\section{Referencias bibliográficas}

Aira Rodríguez, M. J. - Uzquiano Ollero, P. (1996): “Análisis polínico e identificación de carbones en necrópolis gallegas de época romana”, [en] A. Rodríguez Colmenero (coord.), Lucus Augusti I. El amanecer de una ciudad, A Coruña, 47-53.

Álvarez-Fernández, N. - Martínez Cortizas, A. - López-Costas, O. (2020): “Atmospheric Mercury Pollution Deciphered through Archaeological Bones", Journal of Archaeological Science 119, 105-159 (https://doi.org/10.1016/j.jas.2020.105159).

Arce, J.

(1995): "El catastrofismo de Hydacio y los camellos de la Gallaecia", [en] A. Velázquez -

E. Cerrillo - P. Mateos (eds.), Los últimos romanos de Lusitania (=Cuadernos Emeritenses 10), Mérida, 219-229.

(2013): Bárbaros y romanos en Hispania:(400-507 AD), Madrid.

Aufderheide, A. C. - Rodríguez-Martín, C. (1998): The Cambridge Encyclopedia of Human Paleopathology, Cambridge.

Badal, E. - Carrión, Y. - Macías, M. - Ntinou, M. (coords.), (2012): Wood and charcoal. Evidence for human and natural History (=Saguntum. Extra 13), Valencia.

Ballesteros-Arias, P. (2010): "La Arqueología Rural y la construcción de un paisaje agrario medieval: el caso de Galicia", [en] H. Kirchner (ed.), Por una arqueología agraria: perspectivas de investigación sobre espacios de cultivo en las sociedades medievales hispánicas (=BAR International Series 2062), Oxford.

Bejea García, V. (2015): El marisqueo en el noroeste de la Península Ibérica durante la Edad del Hierro y la época romana, Tesis doctoral, Universidad de León.

Bindler, R. (2011): "Contaminated Lead Environments of Man: Reviewing the Lead Isotopic Evidence in Sediments, Peat, and Soils for the Temporal and Spatial Patterns of Atmospheric Lead Pollution in Sweden", Environmental Geochemistry and Health 33, 311-329 (https://doi.org/10.1007/s10653-011-9381-7).

Blanco Freijeiro, A. - Fusté Ara, M. E. - García Alén, A. (1967): “La necrópolis galaicoromana de La Lanzada (Noalla, Pontevedra), II", Cuadernos de Estudios Gallegos 22, 5-23, 129-155.

Brown, P. R. L. (2012): El mundo en la Antigüedad tardía. De Marco Aurelio a Mahoma, Madrid.

Burgess, R. W. (1989): Hydatius: A Late Roman Chronicler in Post-Roman Spain. An Historiographical Study and New Critical Edition of the Chronicle, D. Phil. thesis, Oxford University.

Candelas Colodrón, C. (2004): Análisis de la figura de Hidacio de Chaves a través de los condicionantes socioeconómicos, políticos y culturales de la Gallaecia del siglo V: el Cronicón, Tesis doctoral, Universidade da Coruña.

Carrión Marco, Y. - Peña-Chocarro, L. - Sabato, D. - Checa Gómez, E. - López-Romero González de La Aleja, E. (2015): "Las plantas enterradas: historia del uso y abandono del pozo-depósito de la Tabacalera de Gijón”, [en] Fernández Ochoa - Orejas Saco del Valle - García Díaz - Gil Sendino (eds.), 2015, 210-225.

Carrión, Y. - Kaal, J. - López-Sáez, J. A - López-Merino, L. - Martínez Cortizas, A. (2010): "Holocene Vegetation Changes in NW Iberia Revealed by Anthracological and Palynological Records from a Colluvial Soil", The Holocene 20, 53-66 (https://doi. org/10.1177/0959683609348849).

Costa Vaz, F. - Braga, C. - Tereso, J. P. - Oliveira, C. - Carretero, L. G. - Detry, C. - Marcos, B. - Fontes, L. - Martins, M. (2020): "Food for the Dead, Fuel for the Pyre: Symbolism 
and Function of Plant Remains in Provincial Roman Cremation Rituals in the Necropolis of Bracara Augusta (NW Iberia)", Quaternary International 404, 86-103 (https://doi. org/10.1016/j.quaint.2020.08.054),

Costa Vaz, F. - Martín-Seijo, M. - Carneiro, S. - Tereso, J. P. (2016): "Waterlogged Plant Remains from the Roman Healing Spa of Aquae Flaviae (Chaves, Portugal): Utilitarian Objects, Timber, Fruits and Seeds", Quaternary International 404, 86-103 (https://doi. org/10.1016/j.quaint.2015.09.063).

Chadwick, H. (1976): Priscillian of Avila. The Occult and the Charismatic in the Early Church, Oxford.

Díaz, P. C. (2000): "El reino suevo de Hispania y su sede en Bracara", Memorias de la Real Academia de Buenas Letras de Barcelona 25, 403-423.

Escribano Paño, Ma V. (1996): "El priscilianismo y Gallaecia (ss. IV y V)", [en] M. V. García Quintela (ed.), Las religiones en la historia de Galicia (=Sémata 7-8), Santiago, 251-294.

Fernández Mier, M.

(1999): Génesis del territorio en la Edad Media. Arqueología del paisaje y evolución histórica en la montaña asturiana: El valle del río Pigüeña (=Universidad de Oviedo. Publicaciones del Departamento de Historia y Artes, Área de Historia Medieval 19), Oviedo.

(2013): “Arqueología agraria del norte peninsular: líneas de investigación sobre un paisaje multifuncional. El ejemplo de Asturias", [en] A. García Porras (ed.), Arqueología de la producción en época medieval (=Nakla. Colección de Arqueología y Patrimonio 15), Granada, 408-432.

Fernández Ochoa, C. - Gil Sendino, F. - Salido Domínguez, J. (2015): "Estudio de los materiales arqueológicos”, [en] Fernández Ochoa - Orejas Saco del Valle - García Díaz - Gil Sendino (eds.), 2015, 126-157.

Fernández Ochoa, C. - Orejas Saco del Valle, A. - García Díaz, P. - Gil Sendino, F. (eds.), (2015): La Fábrica de Tabacos de Gijón: arquelogía e historia de un espacio milenario, Gijón.

Fernández Ochoa, C. - Salido Domínguez, J. - García Díaz, P. - Gil Sendino, F. (2015): “El uso de la madera en el periodo tardoantiguo: objetos de la vida cotidiana procedentes de la excavación de la Fábrica de Tabacos de Gijón (Asturias)", Zephyrvs 76, 141-158 (https://doi.org/10.14201/10.14201/zephyrus201).

Fernández Rodríguez, C. (2003): Ganadería, caza y animales de compañía en la Galicia romana: estudio arqueozoológico (=Brigantium 15), A Coruña.

Fernández Rodríguez, C. - Fuertes Prieto, N. (2007): "La romanización del noroeste de la Península Ibérica y las modificaciones en la presencia, uso y consumo de los mamíferos", [en] S. O. Jorge - A. M. S. Bettencourt - I. Figueiral (eds.), A concepção das paisagens e dos espaços na Arqueologia da Península Ibérica. Actas IV Congresso de Arqueologia Peninsular, Faro, 207-217.

Ferré Álvarez, M. D. C. (2003): Contribución al estudio de la arqueoictiofauna holocena en Galicia, Tesis doctoral, Universidade de Santiago de Compostela.

Ferro-Vázquez, C. - Martínez-Cortizas, A. - Nóvoa-Muñoz, J. C. - Ballesteros-Arias, P. - Criado-Boado, F. (2014): "1500 Years of Soil Use Reconstructed from the Chemical Properties of a Terraced Soil Sequence", Quaternary International 346, 28-40 (https:// doi.org/10.1016/j.quaint.2014.03.023).

Ferro Vázquez, M. C. - González Prieto, S. J. - Martínez Cortizas, A. - Criado-Boado, F. (2015): "Deciphering the Evolution of Agrarian Technologies during the Last 1600 Years Using the Isotopic Fingerprint $\left(\delta^{13} \mathrm{C}, \delta^{15} \mathrm{~N}\right)$ of a Polycyclic Terraced Soil", Estudos do Quaternário APEQ 12, 39-53 (https://doi.org/10.30893/eq.v0i12.108). 
González Gómez de Agüero, E. (2013): La ictiofauna de los yacimientos arqueológicos del noroeste de la Península Ibérica, Tesis doctoral, Universidad de León.

Grandal D’Anglade, A. - Serrulla Rech, F. - Tomas Botella, V. - Pérez-Rama, M. - Gómez, M. - Ramil Gonzalez, E. (2015): "Vida y muerte de dos mujeres de Brigantium (NW de Iberia) mediante isótopos estables y antropología forense", Cadernos Laboratorio Xeolóxico de Laxe 38, 47-68.

Grau-Sologestoa, I. (2015): "Livestock Management in Spain from Roman to Post-Medieval Times: A Biometrical Analysis of Cattle, Sheep/Goat and Pig”, Journal of Archaeological Science 54, 123-134 (https://doi.org/10.1016/j.jas.2014.11.038).

Hakenbeck, S. - Mcmanus, E. - Geisler, H. - Grupe, G. -O'Connell, T. C. (2010): "Diet and Mobility in Early Medieval Bavaria: A Study of Carbon and Nitrogen Stable Isotopes", American Journal of Physical Anthropology 143, 235-249 (https://doi.org/10.1002/ajpa.21309).

Harper, K. (2017): The fate of Rome: Climate, Disease, and the End of an Empire, Princeton.

Hong, S. - Candelone, J. P. - Patterson, C. C. - Boutron, C. F. (1996): "History of Ancient Copper Smelting Pollution During Roman and Medieval Times Recorded in Greenland Ice", Science 272, 246-249 (https://doi.org/10.1126/science.272.5259.246).

Jalut, G. - Turu i Michels, V. - Dedoubat, J. J. - Otto, T. - Ezquerra, J. - Fontugne, M. Belet, J. M. - Bonnet, L. - De Celis, A. G. - Redondo-Vega, J. M. - Vidal-Romaní, J. R. - Santos, L. (2010): "Palaeoenvironmental Studies in NW Iberia (Cantabrian range): Vegetation History and Synthetic Approach of the Last Deglaciation Phases in the Western Mediterranean", Palaeogeography, Palaeoclimatology, Palaeoecology 297, 330-350 (https://doi.org/10.1016/j.palaeo.2010.08.012).

Jordana, X. - Malgosa, A. (2004): "Variabilité morphométrique des populations historiques de la Péninsule Ibérique", Antropo 7, 187-194.

Jordana, X. - Malgosa, A. - Casté, B. - Tornero, C. (2019): "Lost in Transition: The Dietary Shifts from Late Antiquity to the Early Middle Ages in the North Eastern Iberian Peninsula", Archaeological and Anthropological Sciences 11, 3751-3763 (https://doi. org/10.1007/s12520-019-00777-9).

Kaal, J. - López-Costas, O. - Martínez Cortizas, A. (2016): “Diagenetic Effects on Pyrolysis Fingerprints of Extracted Collagen in Archaeological Human Bones from NW Spain, as Determined by Pyrolysis-GC-MS", Journal of Archaeological Science 65, 1-10 (https:// doi.org/10.1016/j.jas.2015.11.001).

Kaal, J. - Carrión Marco, Y. - Asouti, E. - Martín Seijo, M. - Martínez Cortizas, A. - Costa Casais, M. - Criado Boado, F. (2011): "Long-term Deforestation in NW Spain: Linking the Holocene Fire History to Vegetation Change and Human Activities", Quaternary Science Reviews 30, 161-175 (https://doi.org/10.1016/j.quascirev.2010.10.006).

Kaal, J. - Martínez Cortizas, A. - Eckmeier, E. - Costa Casais, M. - Santos Estévez, M. - Criado Boado, F. (2008): "Holocene Fire History of Black Colluvial Soils Revealed by Pyrolysis-GC/MS: A Case Study from Campo Lameiro (NW Spain)", Journal of Archaeological Science 35, 2133-2143 (https://doi.org/10.1016/j.jas.2008.01.013).

Kylander, M. E. - Weiss, D. J. - Martínez Cortizas, A. - Spiro, B. - Garcia-Sanchez, R. Coles, B. J. (2005): "Refining the Pre-Industrial Atmospheric Pb Isotope Evolution Curve in Europe Using an 8000 Year Old Peat Core from NW Spain", Earth and Planetary Science Letters 240, 467-485 (https://doi.org/10.1016/j.eps1.2005.09.024).

López Barja de Quiroga, P. (1999): "El poder en la "Gallaecia” romana: Hidacio e Orosio", [en] J. C. Bermejo Barrera (ed.), ¿Quen manda aquí? O poder na historia de Galicia. VII Semana Galega de Historia (=Asociación Galega de Historiadores 14), Santiago de Compostela, 61-72. 
López-Costas, O.

(2012): Antropología de los restos óseos humanos de Galicia: estudio de la población romano y medieval gallega, Tesis doctoral, Universidad de Granada.

(2015): "Taphonomy and Burial Context of the Roman/Post-Roman Funerary Areas (2 $2^{\text {nd }}$ to $6^{\text {th }}$ Centuries AD) of A Lanzada, NW Spain", Estudos do Quaternário APEQ 12, 55-67 (https://doi.org/10.30893/eq.v0i12.111)

López-Costas, O. - Alexander, M. (2019): "Paleodiet in the Iberian Peninsula: Exploring the Connections between Diet, Culture, Disease and Environment Using Isotopic and Osteoarchaeological Evidence", Archaeological and Anthropological Sciences 11, 36533664 (https://doi.org/10.1007/s12520-019-00886-5).

López-Costas, O. - Castro, J. C. - Botella, M. C. - Núñez, M. (2007): "Estudio de la población medieval gallega", [en] A. Martínez-Almagro (ed.), Diversidad Biológica y Salud Humana, Murcia, 535-539.

López-Costas, O. - Kylander, M. - Mattielli, N. - Álvarez-Fernández, N. - Pérez-Rodríguez, M. - Mighall, T. - Bindler, R. - Martínez Cortizas, A. (2020): "Human Bones Tell the Story of Atmospheric Mercury and Lead Exposure at the Edge of Roman World", Science of the Total Environment 710, 136319 (https://doi.org/10.1016/j.scitotenv.2019.136319).

López-Costas, O. - Lantes-Suárez, Ó. - Martínez Cortizas, A. (2016): "Chemical Compositional Changes in Archaeological Human Bones Due to Diagenesis: Type of Bone vs Soil Environment”, Journal of Archaeological Science 67, 43-51 (https://doi. org/10.1016/j.jas.2016.02.001).

López-Costas, O. - Müldner, G.

(2016): "Fringes of the Empire: Diet and Cultural Change at the Roman to Post-Roman Transition in NW Iberia", American Journal of Physical Anthropology 161, 141-154 (https://doi.org/10.1002/ajpa.23016).

(2019): "Boom and Bust at a Medieval Fishing Port: Dietary Preferences of Fishers and Artisan Families from Pontevedra (Galicia, NW Spain) during the Late Medieval and Early Modern Period", Archaeological and Anthropological Sciences 11, 3717-3731 (https://doi.org/10.1007/s12520-018-0733-4).

López-Costas, O. - Müldner, G. - Martínez Cortizas, A. (2015): "Diet and Lifestyle in Bronze Age Northwest Spain: The Collective Burial of Cova do Santo", Journal of Archaeological Science 55, 209-218 (https://doi.org/10.1016/j.jas.2015.01.009).

López-Costas, O. - Sánchez Pardo, J. C. (2016): "Antropología física, arqueología y desigualdad social en las necrópolis medievales de Galicia: hacia una visión de conjunto", [en] Quirós Castillo (ed.), 2016, 43-62.

López-Merino, L. - Martínez Cortizas, A. - Reher, G. S. - López-Sáez, J. A. - Mighall, T. M. - Bindler, R. (2014): "Reconstructing the Impact of Human Activities in a NW Iberian Roman Mining Landscape for the Last 2500 Years", Journal of Archaeological Science 50, 208-218 (https://doi.org/10.1016/j.jas.2014.07.016).

López-Merino, L. - Peña-Chocarro, L. - Ruiz-Alonso, M. - López-Sáez, J. A. - SánchezPalencia, F. J. (2010): "Beyond Nature: The Management of a Productive Cultural Landscape in Las Médulas Area (El Bierzo, León, Spain) during Pre-Roman and Roman Times", Plant Biosystems 144, 909-923 (https://doi.org/10.1080/11263504.2010.491976).

Martín Seijo, M.

(2013): A xestión do bosque e do monte dende a Idade do Ferro a época romana no noroeste da península Ibérica: consumo de combustibles e produción de manufacturas en madeira, Tesis doctoral, Universidade de Santiago de Compostela. 
(2019): "Madera y sal: estructuras y objetos de madera recuperados en las salinas romanas de O Areal (Vigo, Galicia)", [en] Á. Morillo Cerdán - M. H. Hermanns - J. Salido Domínguez (eds.), Ephemeral Archaeology: Products and Perishable Materials in the Archaeological Record of Roman Times, Mainz am Rhein, 179-192.

Martín Seijo, M. - Carrión Marco, Y. (2012): "Shaping Wood: Woodworking during the Iron Age and Roman Period in the Northwest of the Iberian Peninsula", [en] Badal et alii (coords.), 2012, 135-144.

Martín-Seijo, M. - Vila, M. C. (2019): “Oak, Ash and Pine: The Role of Firewood in Funerary Rituals at the Roman Site of Reza Vella (Ourense, Spain)", Archaeological and Anthropological Sciences 11, 1911-1926 (https://doi.org/10.1007/s12520-018-0641-7).

Martínez Cortizas, A. - García-Rodeja, E. - Pontevedra Pombal, X. - Nóvoa Muñoz, J. C. - Weiss, D. - Cheburkin, A. (2002a): "Atmospheric Pb Deposition in Spain during the Last 4600 Years Recorded by Two Ombrotrophic Peat Bogs and Implications for the Use of Peat as Archive", The Science of the Total Environment 292, 33-44 (https://doi. org/10.1016/s0048-9697(02)00031-1).

Martínez Cortizas, A. - García-Rodeja, E. - Weiss, D. (2002b): "Introduction. Peat Bog Archives of Atmospheric Metal Deposition", The Science of the Total Environmen 292, 1-5 (https://doi.org/10.1016/s0048-9697(02)00024-4).

Martínez Cortizas, A. - Kaal, J. - Costa Casais, M. - Chesworth, W. (2009): "Human Activities and Holocene Environmental Change in NW Spain”, [en] J. Sánchez Díaz - S. Asins Velis (eds.), Control de la degradación de los suelos y cambio global. IV Simposio sobre control de la degradación de suelos y cambio global, Valencia, 193-208.

Martínez Cortizas, A. - López-Costas, O. - Orme, L. - Mighall, T. - Kylander, M. E. Bindler, R. - Gallego Sala, Á. (2019): "Holocene Atmospheric Dust Deposition in NW Spain”, The Holocene 30, 507-518 (https://doi.org/10.1177/0959683619875193).

Martínez Cortizas, A. - López-Merino, L. - Bindler, R. - Mighall, T. - Kylander, M. (2013): "Atmospheric Pb Pollution in N Iberia during the Late Iron Age/Roman Times Reconstructed Using the High-Resolution Record of La Molina Mire (Asturias, Spain)", Journal of Paleolimnology 50, 71-86 (https://doi.org/10.1007/s10933-0139705-y).

Martínez Cortizas, A. - Mighall, T. - Pontevedra Pombal, X. - Nóvoa Muñoz, J. C. Peiteado Varela, E. - Piñeiro Rebolo, R. (2005): "Linking Changes in Atmospheric Dust Deposition, Vegetation Change and Human Activities in Northwest Spain during the Last 5300 Years", Holocene 15, 698-706 (https://doi.org/10.1191/0959683605hl834rp).

Martínez Cortizas, A. - Pérez Alberti, A. (1999): Atlas climático de Galicia, Santiago de Compostela

Martínez Cortizas, A. - Pontevedra-Pombal, X. - García-Rodeja, E. - Nóvoa-Muñoz, J. C. - Shotyk, W. (1999): "Mercury in a Spanish Peat Bog: Archive of Climate Change and Atmospheric Metal Deposition", Science 284, 939-942 (https://doi.org/10.1126/ science.284.5416.939).

Martínez-Cortizas, A. - Pontevedra-Pombal, X. - Nóvoa-Muñoz, J. - García-Rodeja, E. (1997): "Four Thousand Years of Atmospheric Pb, Cd and Zn Deposition Recorded by the Ombrotrophic Peat Bog of Penido Vello (Northwestern Spain)", Water, Air, and Soil Pollution 100, 387-403 (https://doi.org/10.1023/A:1018312223189).

Menéndez Bueyes, L. R.

(2013): Medicina, enfermedad y muerte en la España tardoantigua: un acercamiento histórico a las patologías de las poblaciones de la época tardorromana e hispanovisigoda (siglos IV-VIII), Salamanca. 
(2016): “Condiciones de vida y enfermedad en la Tardoantigüedad. Una aproximación desde la parte occidental del antiguo imperio romano", [en] Quirós Castillo (ed.), 2016, 223-243.

Mighall, T. M. - Martínez Cortizas, A. - Biester, H. - Turner, S. E. (2006): "Proxy Climate and Vegetation Changes during the Last Five Millennia in NW Iberia: Pollen and NonPollen Palynomorph Data from Two Ombrotrophic Peat Bogs in the North Western Iberian Peninsula", Review of Palaeobotany and Palynology 141, 203-223 (https://doi. org/10.1016/j.revpalbo.2006.03.013).

Muñoz Sobrino, C. - Ramil-Rego, P. - Gómez-Orellana, L. - Díaz Varela, R. A. (2005): "Palynological Data on Major Holocene Climatic Events in NW Iberia", Boreas 34, 381400 (https://doi.org/10.1111/j.1502-3885.2005.tb01108.x).

Muñoz Sobrino, C. - Ramil-Rego, P. - Rodríguez Guitián, M. (1997): “Upland Vegetation in the North-West Iberian Peninsula after the Last Glaciation: Forest History and Deforestation Dynamics", Vegetation History and Archaeobotany 6, 215-233 (https://doi. org/10.1007/BF01370443).

Murozumi, M. - Chow, T. J. - Patterson, C. (1969): “Chemical Concentrations of Pollutant Lead Aerosols, Terrestrial Dusts and Sea Salts in Greenland and Antarctic Snow Strata", Geochimica et Cosmochimica Acta 33, 1247-1294 (https://doi.org/10.1016/00167037(69)90045-3).

Olesti Vila, O. (2019): “¡Al basurero!: el tratamiento del cuerpo del esclavo romano y tardoromano en algunos yacimientos rurales del N.E. peninsular”, [en] A. Gonzales (ed.), Praxis e ideologías de la Violencia. Para una anatomía de las sociedades patriarcales esclavistas desde la Antigüedad. XXXVIII coloquio del GIREA, Besançon, 429-455.

Oliva, M. - Ruiz-Fernández, J. - Barriendos, M. - Benito, G. - Cuadrat, J. M. - DomínguezCastro, F. - García-Ruiz, J. M. - Giralt, S. - Gómez-Ortiz, A. - Hernández, A. - LópezCostas, O. - López-Moreno, J. I. - López-Sáez, J. A. - Martínez-Cortizas, A. - Moreno, A. - Prohom, M. - Saz, M. A. - Serrano, E. - Tejedor, E. - Trigo, R. - Valero-Garcés, B. Vicente-Serrano, S. M. (2018): "The Little Ice Age in Iberian Mountains", Earth-Science Reviews 177, 175-208 (https://doi.org/10.1016/j.earscirev.2017.11.010).

Peña-Chocarro, L. - Pérez- Jordà, G. - Alonso, N. - Antolín, F. - Teira-Brión, A. - Tereso, J. P. - Montes Moya, E. M. - López Reyes, D. (2019): "Roman and Medieval Crops in the Iberian Peninsula: A First Overview of Seeds and Fruits from Archaeological Sites", Quaternary International 499, 49-66 (https://doi.org/10.1016/j.quaint.2017.09.037).

Piay Augusto, D. (2019): Prisciliano. Vida y muerte de un disidente en el amanecer del Imperio cristiano, Gijón.

Pontevedra-Pombal, X. - Mighall, T. M. - Nóvoa-Muñoz, J. C. - Peiteado-Varela, E. Rodríguez-Racedo, J. - García-Rodeja, E. - Martínez-Cortizas, A. (2013): "Five Thousand Years of Atmospheric Ni, Zn, As, and Cd Deposition Recorded in Bogs from NW Iberia: Prehistoric and Historic Anthropogenic Contributions", Journal of Archaeological Science 40, 764-777 (https://doi.org/10.1016/j.jas.2012.07.010).

Quirós Castillo, J. A. (ed.), (2016): Demografía, paleopatologías y desigualdad social en el noroeste peninsular en época medieval (=Universidad del País Vasco. Documentos de arqueología medieval 10), Bilbao.

Renberg, I. - Bindler, R. - Brännvall, M. L. (2001): "Using the Historical Atmospheric LeadDeposition Record as a Chronological Marker in Sediment Deposits in Europe", The Holocene 11, 511-516 (https://doi.org/10.1191/095968301680223468).

Requejo Pagés, O. (2015): “Ofrendas cerámicas de un contexto funerario de la segunda mitad del siglo IV hasta los inicios de la sexta centuria en el territorio astur transmontano: La 
Necrópolis de Paredes (Siero, Principado de Asturias)", Ex Officina Hispana. Cuadernos de SECAH 2/1, 139-160.

Rodríguez, C. F. (2000): Los macromamíferos en los yacimientos arqueológicos del noroeste peninsular un estudio económico, Tesis doctoral, Universidade de Santiago de Compostela.

Rodríguez Martínez, R. M. - Aboal Fernández, R. - Castro Hierro, V. - Candela Cereijo, C. - Ayán Vila, J. M. (2011): "Una posible factoría prerromana en el noroeste. Primeras valoraciones de la intervención en el Campo de A Lanzada (Sanxenxo, Pontevedra)", Férvedes 7, 159-168.

Santos, L. - Vidal Romani, J. R. - Jalut, G. (2000): "History of Vegetation during the Holocene in the Courel and Queixa Sierras, Galicia, Northwest Iberian Peninsula", Journal of Quaternary Science 15, 621-632 (https://doi.org/10.1002/10991417(200009)15:6<621::AID-JQS524>3.0.CO;2-L).

Schellekens, J. - Buurman, P. - Fraga, I. - Martínez-Cortizas, A. (2011): “Holocene Vegetation and Hydrologic Changes Inferred from Molecular Vegetation Markers in Peat, Penido Vello (Galicia, Spain)", Palaeogeography, Palaeoclimatology, Palaeoecology 299, 56-69 (https://doi.org/10.1016/j.palaeo.2010.10.034).

Silva-Sánchez, N. - López-Costas, O. - Tallón-Armada, R. (2013): "Edafología, palinología y antropología física aplicadas a la arqueología ambiental", Estudos do Quaternário APEQ 9, 1-14 (https://doi.org/10.30893/eq.v0i9.150).

Silva-Sánchez, N. - Martínez Cortizas, A. - López-Merino, L. (2014): “Linking Forest Cover, Soil Erosion and Mire Hydrology to Late-Holocene Human Activity and Climate in NW Spain", The Holocene 24, 714-725 (https://doi.org/10.1177/0959683614526934).

Sobel, M. E. (2013): Lifestyle and social structure: Concepts, definitions, analyses, Amherst (https://doi.org/10.1016/C2013-0-11518-8).

Tallón-Armada, R. - Costa-Casais, M. - Blanco-Chao, R. - Taboada Rodríguez, T. - Martínez Cortizas, A. (2018): "Paleoenvironmental Reconstruction of an Urban Archaeological Site: The Roman Salt Mines of Vigo, Northwest Iberia", Geoarchaeology 33, 112-126 (https://doi.org/10.1002/gea.21648).

Teira Brión, A. M.

(2013): "Dentro y fuera del bosque. La gestión del Prunus avium/cerasus en época romana y medieval en el NW ibérico", Arqueogazte 3, 99-115.

(2019): Cambio e resiliencia na agricultura exestión de recursos vexetais no $N W$ da Península Ibérica (1000 ane-400 dne), Tesis doctoral, Universidade de Santiago de Compostela.

Teira Brión, A. M. - Martín Seijo, M. - De Lombera Hermida, A. - Fábregas Valcarce, R. - Rodríguez Álvarez, X. P. (2012): "Forest Resource Management during Roman and Medieval Cave Occupations in the Northwest of the Iberian Peninsula: Cova do Xato and Cova Eirós (Galicia, Spain)" [en] Badal et alii (coords.), 2012, 159-166.

Valenzuela-Lamas, S. - Detry, C. (2017): "Romanización y arqueozoología en el limes del Imperio. El caso de Lusitania entre la Edad del Hierro y el Bajo Imperio (ss. VIII a.C.-V d.C.)", Archaeofauna 26, 39-51 (https://doi.org/10.15366/archaeofauna2017.26.003).

Varela López, T. A. (1974-75): Estudio antropológico de los restos óseos procedentes de necrópolis visigodas de la Península Ibérica, Tesis Doctoral (=Trabajos de Antropología 17), Madrid.

Zubiaurre Ibáñez, E. (2017): Estrategias de control y gestión de los paisajes mineros del noroeste de Hispania (siglos I-III d. C.), Tesis doctoral, Universidad Complutense de Madrid. 